\title{
Response of global evaporation to major climate modes in historical and future Coupled Model Intercomparison Project Phase 5 simulations
}

\author{
Thanh Le $\mathrm{e}^{1,2}$ and Deg-Hyo Bae $\mathrm{B}^{1,2}$ \\ ${ }^{1}$ Department of Civil \& Environmental Engineering, Sejong University, Seoul, South Korea \\ ${ }^{2}$ Climate Change Adaptation for Water Resources, Sejong University, Seoul, South Korea
}

Correspondence: Deg-Hyo Bae (dhbae@sejong.ac.kr)

Received: 24 August 2019 - Discussion started: 28 August 2019

Revised: 8 February 2020 - Accepted: 10 February 2020 - Published: 11 March 2020

\begin{abstract}
Climate extremes, such as floods and droughts, might have severe economic and societal impacts. Given the high costs associated with these events, developing earlywarning systems is of high priority. Evaporation, which is driven by around $50 \%$ of solar energy absorbed at surface of the Earth, is an important indicator of the global water budget, monsoon precipitation, drought monitoring and the hydrological cycle. Here we investigate the response of global evaporation to main modes of interannual climate variability, including the Indian Ocean Dipole (IOD), the North Atlantic Oscillation (NAO) and the El Niño-Southern Oscillation (ENSO). These climate modes may have an influence on temperature, precipitation, soil moisture and wind speed and are likely to have impacts on global evaporation. We utilized data of historical simulations and RCP8.5 (representative concentration pathway) future simulations derived from the Coupled Model Intercomparison Project Phase 5 (CMIP5). Our results indicate that ENSO is an important driver of evaporation for many regions, especially the tropical Pacific. The significant IOD influence on evaporation is limited in western tropical Indian Ocean, while NAO is more likely to have impacts on evaporation of the North Atlantic European areas. There is high agreement between models in simulating the effects of climate modes on evaporation of these regions. Land evaporation is found to be less sensitive to considered climate modes compared to oceanic evaporation. The spatial influence of major climate modes on global evaporation is slightly more significant for $\mathrm{NAO}$ and the IOD and slightly less significant for ENSO in the 1906-2000 period compared to the $2006-2100$ period. This study allows us
\end{abstract}

to obtain insight about the predictability of evaporation and hence, may improve the early-warning systems of climate extremes and water resource management.

\section{Introduction}

The North Atlantic Oscillation (NAO; e.g., Hurrell et al., 2003), the Indian Ocean Dipole (IOD; Saji et al., 1999; Webster et al., 1999) and the El Niño-Southern Oscillation (ENSO; e.g., Bjerknes, 1969; Neelin et al., 1998) are major modes of global climate variability. These climate modes may have an influence on important drivers of evaporation such as surface temperature (e.g., Arora et al., 2016; Leung and Zhou, 2016; Sun et al., 2016; Thirumalai et al., 2017; Wang et al., 2017), precipitation (Dai and Wigley, 2000), soil moisture (Nicolai-Shaw et al., 2016), humidity (Hegerl et al., 2015) and wind speed (Hurrell et al., 2003; Yeh et al., 2018). Hence, these climate modes are likely to have impacts on global evaporation and transpiration (hereafter simply referred to as "evaporation"). Evaporation, which is driven by around $50 \%$ of the solar energy absorbed at the surface of the Earth (Cavusoglu et al., 2017; Jung et al., 2010), is an important variable contributing to the global water budget, monsoon precipitation, drought monitoring and the hydrological cycle (Friedrich et al., 2018; Kitoh, 2016; Lee et al., 2019; van Osnabrugge et al., 2019; Son and Bae, 2015). Additionally, changes in global evaporation are expected to feedback on global and regional climate. For example, land evaporation is shown to have an influences on carbon cycles (Cheng 
et al., 2017), cloud cover (Teuling et al., 2017) and air temperature (Miralles et al., 2012).

While previous studies emphasize the importance of ENSO (Martens et al., 2018; Miralles et al., 2013), the Atlantic Multidecadal Oscillation, the Tropical Northern Atlantic Dipole, Tropical Southern Atlantic Dipole and the IOD (Martens et al., 2018) on global land evaporation, the role of the NAO remains elusive. In addition, the future influence of these climate modes on global evaporation under a warming environment remain unclear. Climate change and rising temperature might increase surface evaporation (Miralles et al., 2013) and thus, might reduce global water availability and cause change in the hydrological cycle (e.g., Naumann et al., 2018). Moreover, most previous works (e.g., Shinoda and Han, 2005; Xing et al., 2016; Zveryaev and Hannachi, 2011) mainly address the connection between individual climate modes and evaporation; however, the role of other climate modes might not be included in the analyses. As longterm and reliable evaporation data are lacking (e.g., Hegerl et al., 2015; Miralles et al., 2016), climate model simulations provide additional opportunity to examine the impacts of main climate modes on global evaporation. Besides, evaluating the models' consistency in reproducing the impacts of internal climate variability on evaporation is important for understanding the difference between models.

Here we investigate the causal impacts of major climate modes (i.e., ENSO, IOD and NAO) on global terrestrial and oceanic evaporation in Coupled Model Intercomparison Project Phase 5 (CMIP5) model simulations for the 19062000 and the 2006-2100 periods. For this investigation, we use multivariate predictive models and tests of Granger causality which consider the simultaneous impact of climate modes on global evaporation (see Methods Sect. 2.2).

\section{Data and methods}

\subsection{Data}

The data used in the present study were obtained from CMIP5 model simulations. We employ data of historical simulations (experiment name "historical" in CMIP5) and future simulations with a high-emission climate change scenario (experiment name "rcp85" - representative concentration pathway 8.5) (Taylor et al., 2012). The RCP8.5 is a veryhigh-emission scenario with radiative forcing of $8.5 \mathrm{~W} \mathrm{~m}^{-2}$ in 2100 relative to the preindustrial level (van Vuuren et al., 2011). A warming environment in the RCP8.5 scenario increases the frequency of extreme ENSO and IOD events (Cai et al., 2014, 2015) and potentially modulates the impacts of these climate modes on global evaporation. The starting year of historical simulations is roughly 1850, and the ending year is roughly 2005, while the starting year of future simulations is roughly 2006, and the ending year is roughly 2100. The results of the effects of climate modes on evapo- ration are compared between the historical period and the future period. Hence, in our analyses, we only use the data for the 1906-2000 historical period as a reference (with similar data length) for the future period 2006-2100. We use different data variables, including monthly sea level pressure (i.e., "psl" in CMIP5 datasets), sea surface temperature (i.e., "ts") and evaporation (i.e., "evspsbl"). For each model, we only utilize one simulation (i.e., "r1ilp1"). The models employed in this study are listed in Table S1 (Supplement). As we use 15 different models for our analysis, the uncertainties related to the effects of climate modes on evaporation are reduced. The results based on multi-model mean are generally better and more reliable than single model results (e.g., Weigel et al., 2010). Terrestrial evaporation is the flux of water at the surface into the atmosphere due to transformation of both solid and liquid phases to vapor (from vegetation and underlying surface). Most of the climate models do not provide separately the data of evaporation from canopy (i.e., transpiration) and water evaporation from soil (i.e., evaporation), which complicates attributing changes in evaporation to canopy or soil related processes.

There might exist model biases in simulating ENSO (e.g., Taschetto et al., 2014), the IOD (Chu et al., 2014; Weller and Cai, 2013) and NAO (Gong et al., 2017; Lee et al., 2018), and there is uncertainty in the capability of land surface models in modeling evaporation (Mueller and Seneviratne, 2014; Wang and Dickinson, 2012). However, CMIP5 data are useful for a better understanding of past and future climate and provides additional understanding about the connections between major climate modes and global evaporation.

\subsection{Methods}

The NAO index (Hurrell et al., 2003) is computed as the first empirical orthogonal function (EOF) of borealwinter (December-January-February - DJF) sea level pressure (SLP) anomalies in the North Atlantic area $\left(90^{\circ} \mathrm{W}-\right.$ $40^{\circ} \mathrm{E}, 20-70^{\circ} \mathrm{N}$ ). We compute the dipole mode index (DMI) (Saji et al., 1999) as the discrepancy of sea surface temperature (SST) anomalies between the western tropical Indian Ocean $\left(50-70^{\circ} \mathrm{E} ; 10^{\circ} \mathrm{N}-10^{\circ} \mathrm{S}\right)$ and the southeastern tropical Indian Ocean $\left(90-110^{\circ} \mathrm{E} ; 0^{\circ} \mathrm{N}-10^{\circ} \mathrm{S}\right)$ in the boreal fall (September-October-November - SON). We define the ENSO index as the average sea surface temperature anomalies in the Niño 3.4 region $\left(120-170^{\circ} \mathrm{W} ; 5^{\circ} \mathrm{N}-5^{\circ} \mathrm{S}\right)$ during boreal winter. We include ENSO, the IOD and NAO in our analyses as these indices are three major climate modes of the tropical Pacific, tropical Indian and North Atlantic oceans. These climate modes are the main sources of global climate variability at interannual timescales (e.g., Abram et al., 2003; Hurrell et al., 2003; McPhaden et al., 2006).

We evaluate the causal effects of a climate mode (i.e., NAO, DMI or ENSO) on evaporation by using the following predictive model (e.g., Mosedale et al., 2006): 
$X_{t}=\sum_{i=1}^{p} \alpha_{i} X_{t-i}+\sum_{i=1}^{p} \beta_{i} Y_{t-i}+\sum_{j=1}^{m} \sum_{i=1}^{p} \delta_{j, i} Z_{j, t-i}+\varepsilon_{t}$,

where $X_{t}$ is the annual mean (or seasonal mean) evaporation for year $t, Y_{t}$ is the selected index (i.e., ENSO, NAO or DMI) for evaluating the causal effects on evaporation for year $t$, $Z_{j, t}$ is the confounding variable $j$ for year $t, p \geq 1$ is the order (or the number of lagged time series) of the causal model, and $m$ is the total number of confounding variables. The optimal order $p$ is computed by minimizing the Bayesian information criterion or Schwarz criterion (Schwarz, 1978). We note that the optimal orders might be different for each grid cell, depending on evaporation data of the selected grid cell. The optimal orders are normally less than 8 in our analysis, suggesting that the impact of major climate modes on evaporation is evaluated at interannual timescales. Confounding variables (e.g., if NAO is the selected index of possible causal influence on evaporation, the confounding variables are DMI and ENSO) may have impacts on the links between the selected index and global evaporation. There are two forms of confounding variables in our analysis; hence, $m$ is equal to 2 in Eq. (1). The regression coefficients $\alpha_{i}, \beta_{i}$ and $\delta_{j, i}$ and the noise residuals $\varepsilon_{t}$ are computed by using multiple linear regression analysis and least-squares method. All climate indices and evaporation data are normalized (by using a $z$ score) and detrended (by subtracting the trending line from given data; the trending line or the best-fit line is identified using least-squares method). Detrending the data (for standardizing) does not alter the results and conclusions.

We apply the test for Granger causality for the predictive model described in Eq. (1). Specifically, in order to assess the causal influence from $Y$ to $X$, we compute the probability of the null hypothesis for an absence of Granger causality from $Y$ to $X$. The model shown in Eq. (1) is defined as a complete predictive model where all variables (i.e., past data of evaporation and climate indices) are used to estimate evaporation. The null model of no causal effects from a given climate mode (i.e., variable $Y$ ) to evaporation is defined by removing the terms related to $Y$ (i.e., by setting $\beta_{i}=0$, with $i=1, \ldots, p)$ in Eq. (1). The complete model and the null model are then compared by using the following indicator:

$L_{Y \rightarrow X}=n\left(\log \left|\Omega_{p, \beta_{i}=0}\right|-\log \left|\Omega_{p}\right|\right)$,

where $\left|\Omega_{p}\right|$ is the determinant of the covariance matrix of the noise residual and $\mathrm{n}$ is the length of the data time series. We test the significance of the complete model by comparing the $L_{Y \rightarrow X}$ indicator against a $\chi_{p}^{2}$ null distribution. This test results in a probability for no causal effect of the considered variable $Y$ on evaporation. Additional information on the test of Granger causality is explained in earlier works (e.g., Le, 2015; Le et al., 2016). The techniques employed in the present study, which are designed to detect the causal relationship, provide a robust assessment about the causal influence of the considered climate mode on global evaporation. In addition, these approaches account for the concurrent influence of confounding variables and hence, provide more realistic evidence of the response of global evaporation to major climate modes.

Modes of climate variability might be correlated to each other, and this correlation might have effects on the relationship between these modes and other variables (e.g., evaporation) (Gonsamo et al., 2016; Martens et al., 2018). However, in the approach of Granger causal analysis, the conclusion for the causal effects from variable $Y$ (i.e., the considered climate mode) to variable $X$ (i.e., evaporation) is independent from the relationship between $Y$ and other factors (i.e., the relationship between climate modes) (Mosedale et al., 2006; Stern and Kaufmann, 2013).

We apply the methods described above to all the single models. We then rescale the results of a single model to $1^{\circ}$ longitude $\times 1^{\circ}$ latitude spatial resolution. We use the rescaled results to compute the multi-model mean, which is shown as a map of probability for no Granger causal impact from the individual climate mode to global evaporation.

We note that the temporal resolution of all analyses is yearly (i.e., the index $t$ in Eq. 1 denotes year). Although the definition of the predictand (i.e., $X_{t}$ in Eq. 1) is either the annual mean or seasonal mean values, the analyses related to Granger causality are computed on annual basis. We report the analyses using the annual mean of evaporation (i.e., the predictand $X_{t}$ ) as the main results of this study (Figs. 1-7), while the analyses using the seasonal mean of evaporation provide additional information (Figs. S3-S4, S6-S7 and S9S10 in the Supplement).

\section{Results and discussions}

\subsection{ENSO influence on evaporation}

The probability maps of no Granger causality between ENSO and global evaporation for the periods 1906-2000 and 20062100 are shown in Fig. 1. In both periods, ENSO is more likely to have an influence on numerous regions (highlighted in brown shades) of both hemispheres, including middle Asia (regions close to the Caspian Sea; details are shown in Fig. S1a in the Supplement), the Indian Ocean, southeastern Asia, Australia (Fig. S1b), the tropical Pacific and northeastern South America (i.e., Amazonia, Fig. S1c), and the Pacific coast of America (Fig. S1d). There is high agreement between models (indicated by stippling in Fig. 1) in simulating ENSO-evaporation connection of these regions. ENSO might indirectly influence global evaporation by modulating regional climate factors associated with evaporation processes. For example, ENSO significantly influences nearsurface wind, which is the main contributor to variations of evaporation (Xing et al., 2016). The ENSO impacts on 
a large part of the tropical Pacific Ocean are robust at $5 \%$ and $10 \%$ significance levels (here we reject the null hypothesis of the absence of Granger causal effects between ENSO and evaporation at $5 \%$ and $10 \%$ significance levels; hence, we conclude that there is a significant causal impact; we note that the $5 \%$ and $10 \%$ significance levels are computed from the test for the absence of Granger causality). Further analyses reveal that ENSO has significant impacts on SST (Fig. S2a) and zonal winds (Fig. S2b) over the tropical Pacific for the 1906-2000 period (similar patterns are observed for the 2006-2100 period, not shown). Hence, the influence of ENSO on evaporation might be associated with the wind-evaporation-SST (WES) effect (Cai et al., 2019). The WES effect occurs when warm (cold) water becomes warmer (colder) due to a decrease (increase) in evaporation and weakened (strengthened) surface winds. Besides, ENSO is known to induce changes in global precipitation with a decrease in rainfall in Africa, southeastern Asia, Indonesia, Australia and Amazonia during the El Niño phase (Dai and Wigley, 2000) and thus indirectly influences evaporation of these regions. ENSO causal effects on global precipitation are shown in Fig. S2c, which indicates the close connection between precipitation and evaporation processes in several regions (e.g., the tropical Pacific, Australia, Amazonia and regions closed to the Caspian Sea).

Additional analyses show a more robust influence from ENSO on global evaporation in the boreal spring compared to other seasons (Fig. S3 in the Supplement). The ENSO influence on boreal-winter evaporation is mainly found in the tropical Pacific, while land evaporation is less likely to be influenced by ENSO in winter (Fig. S3a). The limited response of Northern Hemisphere boreal-winter evaporation to ENSO might be related to a low energy supply (i.e., incoming solar radiation), which leads to a reduction in land evaporation (Martens et al., 2018). Although ENSO strength peaks in boreal winter, the weak response of evaporation to ENSO during this specific time of the year suggests the important role of other internal climate modes or external factors (i.e., solar radiation). The boreal-winter evaporation in the Southern Hemisphere might be controlled by local background conditions (e.g., surface temperature) and other major climate modes (e.g., Southern Annular Mode - SAM). The response of global evaporation to ENSO is found to be the most robust in boreal spring and gradually decreases in summer, fall and winter (Figs. S3 and S4). These results indicate the persistent and lagged influence of ENSO on regional evaporation (e.g., Australia, northeastern South America and the tropical Pacific are influenced during boreal spring, summer and fall). The seasonal connection between ENSO and global evaporation in future simulations (Fig. S4) shows similar patterns compared to historical simulations (Fig. S3). (a) MODELS MEAN: ENSO - EVAPORATION PERIOD 1906-2000
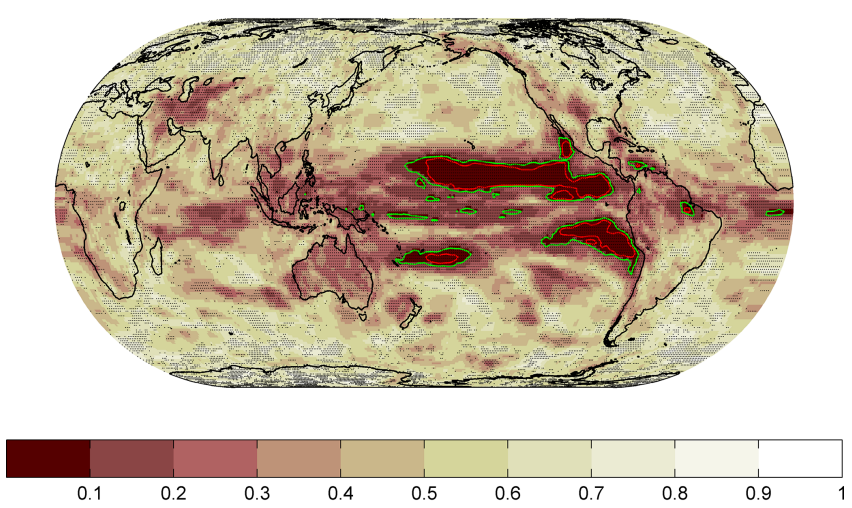

(b)
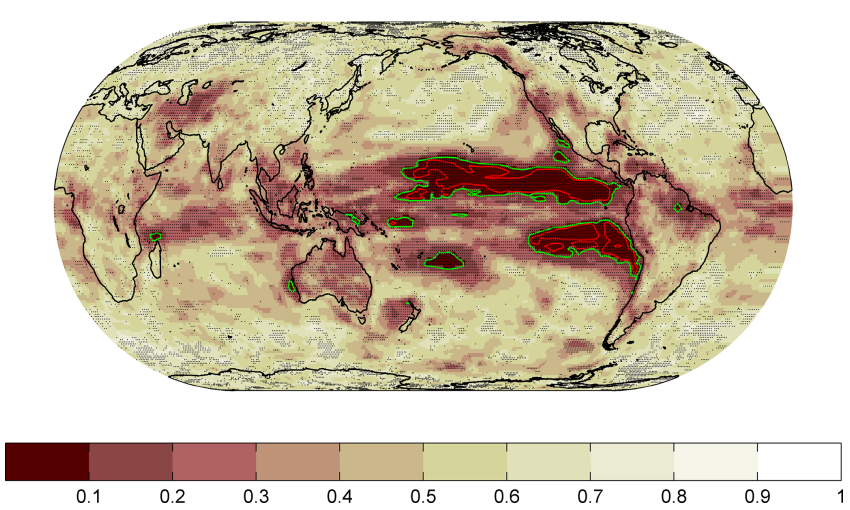

Figure 1. Multi-model mean probability map for the absence of Granger causality between ENSO and annual mean evaporation for the periods 1906-2000 (a) and 2006-2100 (b). Stippling demonstrates that at least $70 \%$ of models show agreement on the mean probability of all models at a given grid point. An individual model's agreement is determined when the difference between the multi-model mean probability and the selected model's probability is less than 1 standard deviation of multi-model mean probability. The green (red) contour line designates a $p$ value of $0.1(0.05)$. Brown shades indicate low probability for the absence of Granger causality. ENSO: El Niño-Southern Oscillation.

\subsection{IOD influence on evaporation}

Figure 2 describes the evaporation response to the IOD which is mainly found in the Indian Ocean and the tropical Pacific. The IOD impacts are shown to be significant in the western tropical Indian Ocean close to the eastern coast of Africa (Fig. 2a and b; see Fig. S5a for additional details). The evaporation response in the western tropical Indian Ocean to the IOD may be associated with the impact of the IOD on short rains in eastern Africa (Behera et al., 2006; Black et al., 2003). The IOD signature is also found in the areas close to the Horn of Africa (Fig. 2a). This result is in agreement with previous work (Martens et al., 2018) which proposed a possible evaporation response of the Horn of Africa to positive phase of the IOD. The IOD shows remote control of evapo- 
(a) MODELS MEAN: IOD - EVAPORATION PERIOD 1906-2000
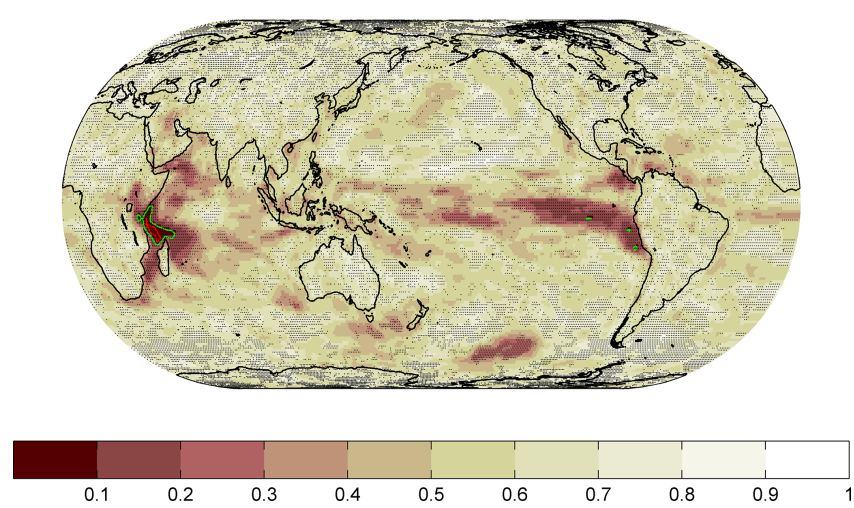

(b) MODELS MEAN: IOD - EVAPORATION PERIOD 2006-2100
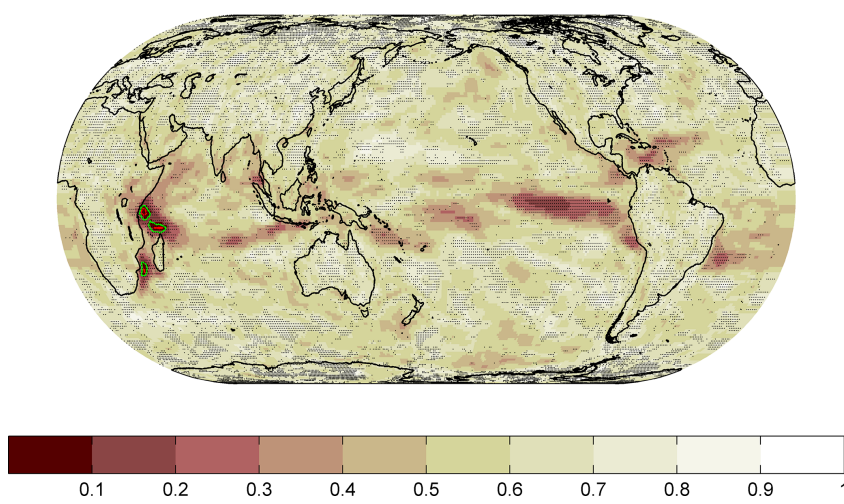

Figure 2. As in Fig. 1 but for Granger causality between the IOD and annual mean evaporation. IOD: Indian Ocean Dipole.

ration in parts of the tropical Pacific, especially the eastern regions (Fig. S5b). This teleconnection might be associated with the IOD effects on ENSO and SST in the eastern parts of the tropical Pacific (e.g., Izumo et al., 2010; Le and Bae, 2019). In historical simulations (Fig. 2a), the IOD impacts might reach as far as the Southern Ocean (region close to 150 to $120^{\circ} \mathrm{W} ; 45$ to $60^{\circ} \mathrm{S}$ ), where there is high agreement between models. This IOD-Southern Ocean teleconnection might be indirect and is possibly related to other major climate mode of the Southern Hemisphere (e.g., SAM).

Although the IOD is shown to contribute to droughts in eastern Asia (Kripalani et al., 2009) and Australia (Ashok et al., 2003; Cai et al., 2009; Ummenhofer et al., 2009), our analyses imply that the IOD impacts on evaporation of these regions are unclear, particularly in the future period of 2006-2100 (Figs. 2b, S6 and S7). Additionally, there is uncertainty in the impact of the IOD on evaporation in other regions, including the Middle East, southern Asia and southeastern Asia, where there is complex interactions between different climate modes (e.g., ENSO, the IOD and the Indian summer monsoon rainfall; Cai et al., 2011; Le and Bae, 2019). Unlike seasonal responses of evaporation to ENSO (Figs. S3 and S4), the seasonal responses of evaporation to the IOD indicate similar patterns between different times of the year (Figs. S6 and S7). Specifically, in all four seasons, the IOD influence on evaporation is mainly shown in parts of the tropical Indian and Pacific oceans. Although there is still uncertainty, the IOD signal is found in evaporation change of Amazonia (i.e., northeastern South America; Figs. S6a and S7a) in boreal winter (December-February) for several model simulations. These results are in agreement with previous study (Martens et al., 2018), which showed the sensitivity of evaporation in the rainforest to the IOD.

\subsection{NAO influence on evaporation}

The global evaporation response to NAO, which is limited in the Northern Hemisphere, is shown in Fig. 3. NAO mainly contributes to change in evaporation of the North Atlantic European sector where high agreement between models is found (see Fig. S8 for additional details). This conclusion shows consistency with earlier works and indicates the capability of models in simulating the connection between NAO and regional evaporation. Particularly, the positive phase of NAO leads to changes in temperature; the transport of atmospheric moisture; and precipitation in northern, central and western Europe and parts of southern Europe and thus causes change in evaporation (Hurrell et al., 2003). Given significant economic losses from floods in Europe caused by NAO (Hurrell et al., 2003; Zanardo et al., 2019), the predictability of regional evaporation using the NAO index might be potentially helpful to mitigate the flood impacts. There is uncertainty of NAO impacts on the southern North Atlantic and eastern Europe. In several models, the NAO impact is found in small areas of the eastern tropical Pacific and South Atlantic (Fig. 3a). NAO might also influence evaporation in parts of central North America and the coast of northeastern South America; however, these signatures are unclear (Fig. 3a). The sensitivity of evaporation in the western coast of North America shown in Fig. 3a is somewhat in agreement with the findings of a previous study (Martens et al., 2018).

The seasonal evaporation response to NAO is much weaker in boreal fall and winter compared to spring and summer (Figs. S9 and S10). In the Northern Hemisphere, this result might be due to a decrease in seasonal solar radiation (Martens et al., 2018). The NAO impacts on northwestern Europe in boreal spring (Figs. S9b and S10b) suggests several months lagged effect of NAO on evaporation of this region. The global evaporation response to NAO is the most robust in boreal spring where NAO signature might exist in a large area of the northern Eurasian continent and parts of the Pacific Ocean (Fig. S9b).

\subsection{Comparing the impacts of different climate modes}

Figure 4 shows the difference in multi-model mean probability for the absence of Granger causality between a pair of climate modes and annual mean evaporation. Specifically, the 
(a)
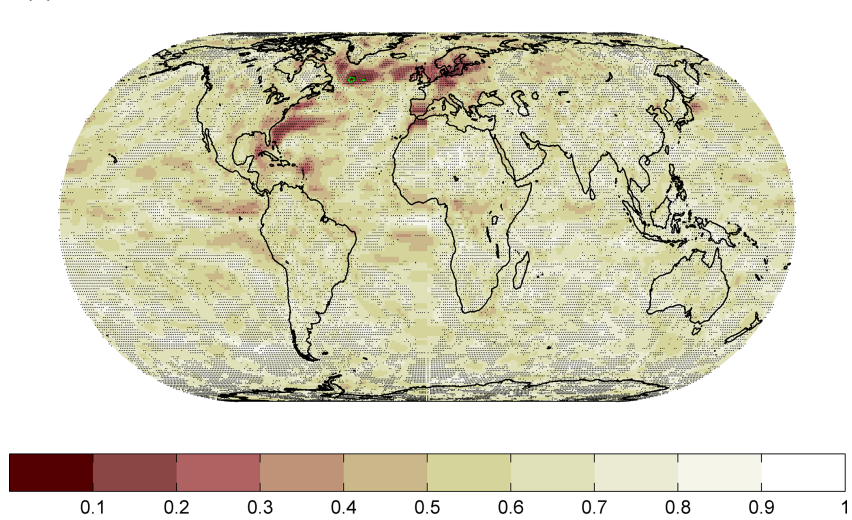

(b)
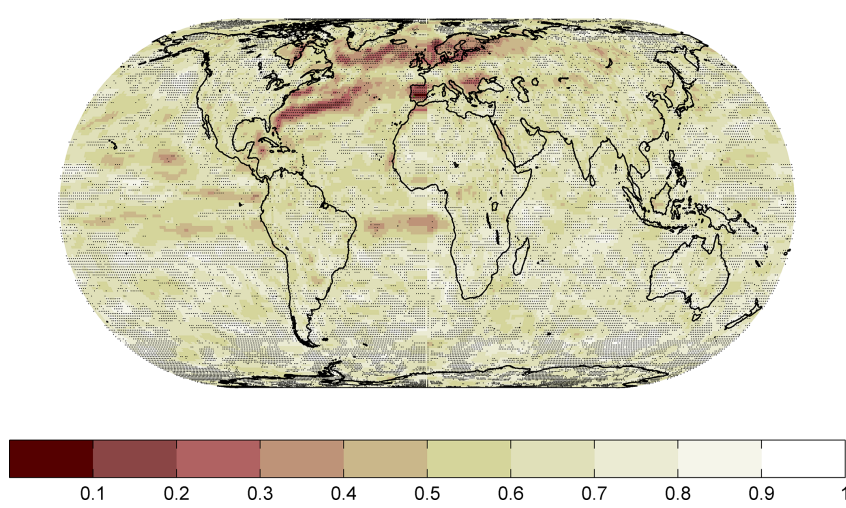

Figure 3. As in Fig. 1 but for Granger causality between NAO and annual mean evaporation. NAO: North Atlantic Oscillation.

effects of ENSO on evaporation are more significant compared to NAO in large parts of the tropical region (highlighted in blue shades, which indicate a lower probability of no causal impacts), while NAO effects are more significant in the high-latitude region of the Northern Hemisphere (highlighted in red shades), especially regarding the North Atlantic European sector (Fig. 4a and d). We observe a stronger signature of ENSO compared to the IOD in the Middle East, the Pacific coast of North America and large parts of the tropics, except for the western tropical Indian Ocean (Fig. $4 \mathrm{~b}$ and e). Figure $4 \mathrm{e}$ indicates the increase in ENSO spatial impact over the western Indian Ocean in the 21st century compared to 20th century. Interestingly, the IOD effects are found to be slightly stronger compared to ENSO in the North Pacific and North Atlantic, suggesting the potential role of the IOD in these regions. The impacts of NAO are more significant compared to the IOD in the North Atlantic European sector, while IOD impacts are stronger in the tropical Pacific and Indian oceans and high-latitude region of the Southern Hemisphere (Fig. 4c and f). Overall, ENSO is the dominant mode of tropical evaporation, while NAO largely contributes to regional evaporation in the high-latitude region of the Northern Hemisphere.

\subsection{Discussions}

The map of the ENSO-evaporation connection presented here (Figs. 1, S1, S3 and S4) confirms the results obtained previously (e.g., ENSO influence on evaporation of Australia and Amazonia, where there is high consistency between models as shown in Fig. 1). The results shown here (Figs. 1 and S2c) are partly in agreement with a previous study (Miralles et al., 2013), which showed lower evaporation during El Niño events due to a decrease in precipitation in eastern and central Australia and eastern South America. In addition, the robust signature of ENSO on evaporation of tropical regions is consistent with the findings of Miralles et al. (2013), which showed negative (positive) anomalies of evaporation for most of the tropics under El Niño (La Niña) conditions. Besides, our results also show new features of the connection between ENSO and global evaporation. Specifically, ENSO is more likely to have an influence on the Pacific coasts of both North and South America. The IOD is suggested to be the main climate mode to have impacts on evaporation of both hemispheres (Martens et al., 2018); however, our results indicate that ENSO influence also has similar characteristics (Figs. 1, S1 and S3). In addition, there is uncertainty of ENSO impacts on land evaporation, especially regarding the regions of southern Asia, Africa and southern South America. The result of ENSO influence on eastern Australia shows consistency with past findings (Martens et al., 2018; Miralles et al., 2013); however, we further indicate that there is also close connection between western Australia evaporation and ENSO variations (Figs. 1, S1 and S3). In fact, evaporation in the Australian continent was shown to have highest sensitivity to ENSO conditions compared to other continents (Miralles et al., 2013). Additionally, our results suggest that ENSO is more likely to have impacts on evaporation of Australia during both the historical period of 1906-2000 and future period 2006-2100. We note that in the present study, we use longer data periods (i.e., 1906-2000 and 2006-2100 model simulations) compared to recent works (e.g., 19822012 in Martens et al., 2018; 1980-2011 in Miralles et al., 2013). Hence, the length of the data period might affect the statistical significance tests and the interpretation of results. There are different factors that contribute to the ambiguity of climate mode impacts on evaporation of several regions (e.g., southern Asia, Africa and southern South America). Specifically, these factors include the large discrepancies of current estimations of land evaporation for recent decades (Dong and Dai, 2017; Miralles et al., 2016), the limitations of climate models in simulating climate modes (Gong et al., 2017; Lee et al., 2018; Taschetto et al., 2014; Weller and Cai, 2013) and the overestimation of simulated evaporation in most regions (Mueller and Seneviratne, 2014). Specifically, there are systematic biases in simulating yearly average evaporation in Australia, China, western North America, Europe, Africa and parts of Amazonia (Mueller and Seneviratne, 2014). Thus, these biases contribute to the uncertainties in the effects of 
MODELS MEAN OF DIFFERENCE BETWEEN ENSO AND NAO - EVAPORATION· PERIOD 1906-2000

(a)
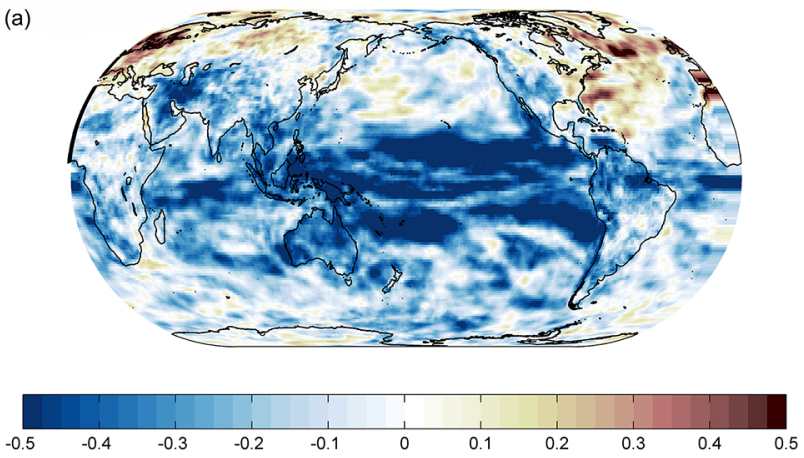
MODELS MEAN OF DIFFERENCE BETWEEN ENSO AND IOD - EVAPORATION: PERIOD 1906-2000

(b)
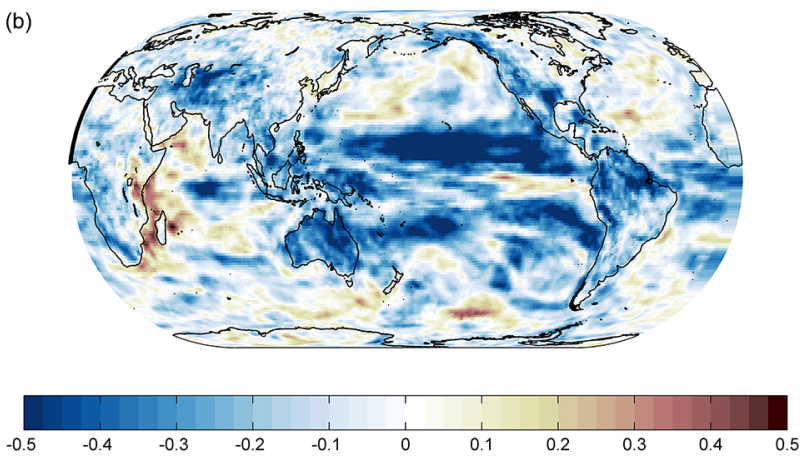
MODELS MEAN OF DIFFERENCE BETWEEN NAO AND IOD - EVAPORATION: PERIOD 1906-2000

(c)
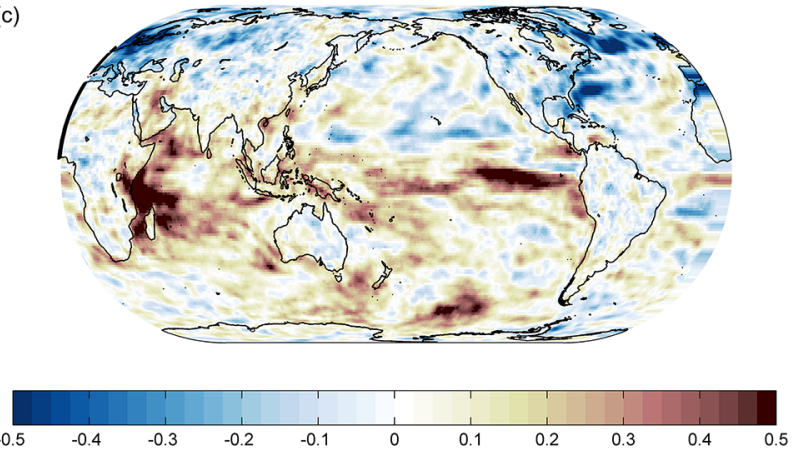

MODELS MEAN OF DIFFERENCE BETWEEN ENSO AND NAO - EVAPORATION. PERIOD 2006-2100

(d)
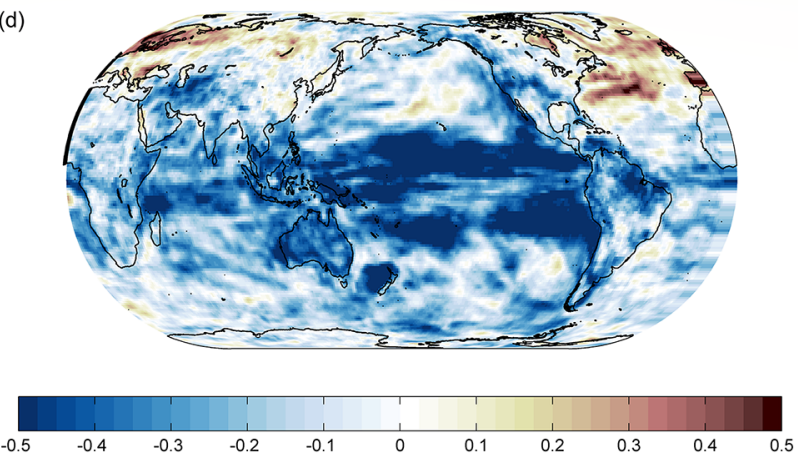

MODELS MEAN OF DIFFERENCE BETWEEN ENSO AND IOD - EVAPORATION: PERIOD 2006-2100

(e)
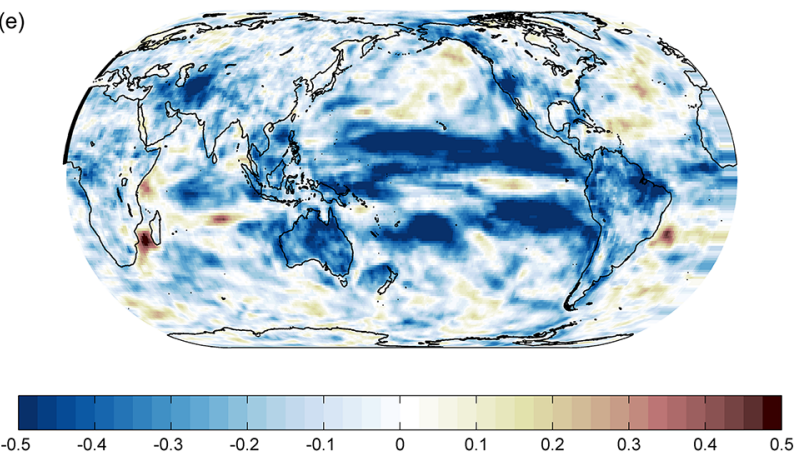

MODELS MEAN OF DIFFERENCE BETWEEN NAO AND IOD - EVAPORATION: PERIOD 2006-2100

(f)
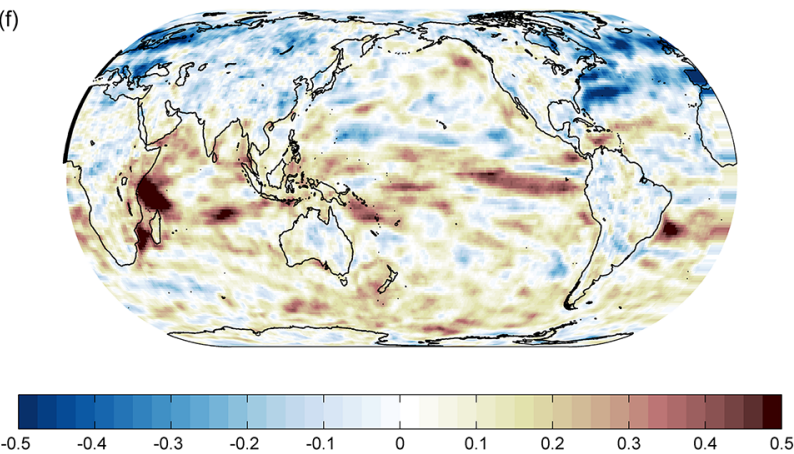

Figure 4. Difference in multi-model mean probability for the absence of Granger causality between a pair of climate modes and annual mean evaporation. The results are shown for the periods 1906-2000 (a, b, c) and 2006-2100 (d, e, f). ENSO minus NAO (a, d). ENSO minus the IOD (b, e). NAO minus the IOD $(\mathbf{c}, \mathbf{f})$. Blue shades indicate a lower probability for the absence of Granger causality. ENSO: El Niño-Southern Oscillation. NAO: North Atlantic Oscillation. IOD: Indian Ocean Dipole.

climate modes on evaporation. Nevertheless, the methods based on multi-model mean and Granger causality tests (see Sect. 2.2) help to reduce the uncertainties and provide robust results and conclusions.

Figure 5 shows the fraction area of Earth surface for land and ocean with a probability of the absence of Granger causality between climate modes and evaporation less than 0.1 (i.e., $p$ value $<0.1$; here, the null hypothesis of no Granger causality from climate modes to evaporation is rejected at a $10 \%$ significance level; hence, we conclude that there are significant causal effects; we note that the fraction area is substantially smaller if $p$ value $<0.05$ ). Specifically, during the period 1906-2000, nearly $1.039 \%$ of land area is affected by ENSO at a $10 \%$ significance level, while the affected land areas by NAO and the IOD are $0 \%$ and $0.017 \%$, respectively (Fig. 5a). The area of oceanic evaporation influenced by ENSO, NAO and the IOD are $2.908 \%, 0.01 \%$ and $0.196 \%$, respectively (Fig. 5a). We observe an increase in land area affected by ENSO to $1.38 \%$ during the 2006-2100 period, while the affected land areas by NAO and the IOD are $0 \%$ (Fig. $5 \mathrm{~b}$ ). The increase of ENSO effects on land evaporation might be associated with the increase in frequency of 
extreme ENSO events in the future period (Cai et al., 2015). The area of oceanic evaporation influenced by ENSO, NAO and the IOD are $2.944 \%, 0.003 \%$ and $0.122 \%$, respectively (Fig. 5b). This result shows a minor decrease in NAO and IOD effects on oceanic evaporation during the 2006-2100 period compared to the 1906-2000 period. Figure S11 shows additional analyses for the fraction area of Earth surface for land and ocean with a probability for the absence of Granger causality between climate modes and evaporation less than 0.25 (i.e., climate modes are unlikely to have no causal effects on evaporation; Stocker et al., 2013). Figure S11 indicates that the land and ocean area influenced by the IOD is slightly higher compared to NAO. The influence of climate modes on land evaporation shown in the present study is generally lower than the results reported in previous works (e.g., Martens et al., 2018). This difference is due to the use of different methods and different data periods.

The considered climate modes (i.e., ENSO, NAO and the IOD) are more likely to have an influences on global evaporation over oceans, while they have limited signature in change of land evaporation for many regions (Figs. 1, 2, 3, 5 and S11). These results indicate the role of other factors in modulating land evaporation. Particularly, the influence of major climate modes on land evaporation might be offset by other factors like greenhouse gases, aerosols or solar radiation (Dong and Dai, 2017; Hegerl et al., 2015; Liu et al., 2011). Besides, climate modes may affect meteorological variables that do not drive land evaporation dynamics. For instance, NAO might affect precipitation (water availability) in northern Europe during winter (Hurrell et al., 2003), but in wintertime, land evaporation is mainly driven by solar radiation in this region. Thus, NAO will apparently only have a small (or no) impact on the dynamics of land evaporation in that case. The impacts of climate modes on ocean evaporation contribute to change in the global hydrological cycle as ocean evaporation might affect land water cycle by inducing change in regional precipitation (Diawara et al., 2016). For example, the evaporation of the eastern North Pacific is the main moisture supply for precipitation in California (Wei et al., 2016).

Changes in the spatial influences of major modes of climate variability on regional evaporation for the future period 2006-2100 and the historical period 1906-2000 depend on each climate mode (Figs. 1, 2 and 3). Analyses in details of the difference between these two periods are shown in Fig. 6. Specifically, the fraction area of Earth surface showing a lower probability of ENSO effects for the 2006-2100 period is approximately $52.9 \%$ (Fig. 6a). This result indicates that ENSO slightly expands the impacted regions (highlighted in red shades, Fig. 6a) during the 2006-2100 period compared to the 1906-2000 period. Conversely, the fraction area of Earth surface for effects of NAO and the IOD during the 2006-2100 period are decreased with $47.2 \%$ and $45.7 \%$, respectively (Fig. $6 \mathrm{~b}$ and c). These results suggest that, for several regions of declining impacts of climate modes (high-
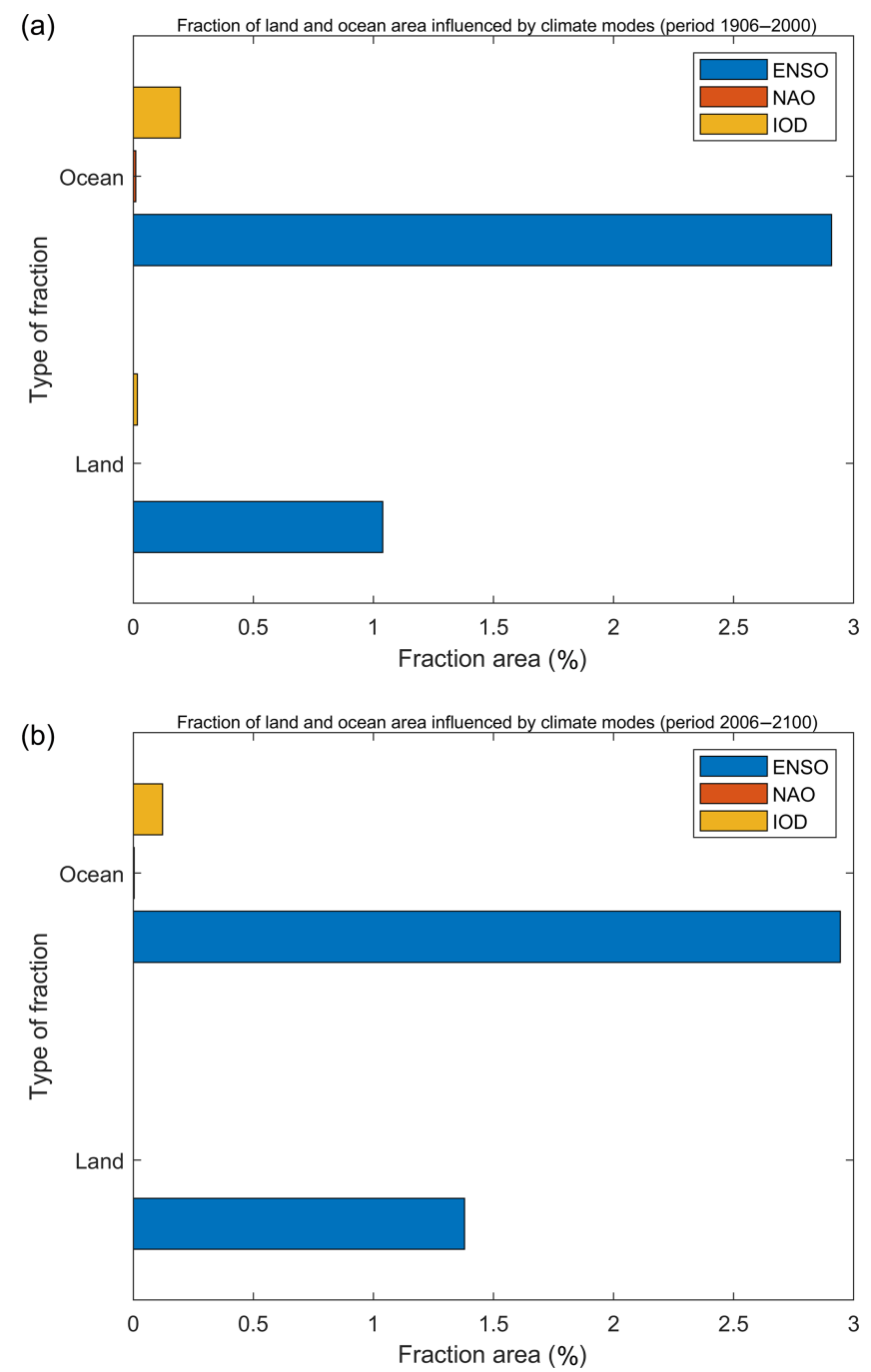

Figure 5. Fraction of Earth surface for land and ocean with the probability for the absence of Granger causality between climate modes and evaporation less than 0.1 (i.e., $p$ value $<0.1$ ). The results are shown for the influence of an individual climate mode on annual mean evaporation for the periods 1906-2000 (a) and 20062100 (b). Fraction areas influenced by ENSO, NAO and the IOD are shown in blue, red and yellow bars, respectively. Several fraction areas are close to zero. ENSO: El Niño-Southern Oscillation. NAO: North Atlantic Oscillation. IOD: Indian Ocean Dipole.

lighted in blue shades, Fig. 6), the important drivers of evaporation processes in the 21 st century (e.g., precipitation, nearsurface air temperature, wind speed and soil moisture) tend to be not affected by the modes of climate variability in the models. For example, the response of regional evaporation to climate warming depends on precipitation (Parr et al., 2016; Zhang et al., 2018), and a projected rise of surface temperature is shown to mainly contribute to the increase in regional evaporation (Laîné et al., 2014). Because the volume of moisture carried by air increases with air temperature, the atmospheric water vapor demand is expected to increase with ris- 
ing air temperature and rising greenhouse gases concentration (Miralles et al., 2013). In addition, the declines in pan evaporation in southern and western Australia are mainly caused by decreases in wind speeds (Stephens et al., 2018).

The dominance of an individual climate mode on evaporation is summarized in Fig. 7 for historical and future periods. Figure 7 shows the regions where the lowest probability for the absence of Granger causality between climate modes and evaporation is less than 0.25 (i.e., climate modes are unlikely to have no causal effects on evaporation). This result indicates the important role of ENSO on global evaporation with dominant effects in the tropical Pacific and parts of middle Asia, southeastern Asia, Australia and northeastern South America. The IOD has dominant effects in the western tropical Indian Ocean and a small part of the eastern tropical $\mathrm{Pa}-$ cific, while NAO is a dominant mode in the North Atlantic and European regions. The shift from one dominant climate mode to another indicates a shift in the dynamics related to their respective climate modes, which could change the timing and magnitude of evaporation. There is a minor change of the dominance of climate modes between historical and future periods, with a slight reduction in the dominance of the IOD in the future.

\section{Conclusions}

The CMIP5 historical and RCP8.5 future simulations provide an opportunity to assess the influence of major climate modes on global evaporation, which plays an important role in the hydrological cycle, drought monitoring and water resource management. This paper employed tests of Granger causality and showed vigorous evaluation of possible impacts of NAO, the IOD and ENSO on global evaporation.

The results show that ENSO is likely to have impacts on evaporation of different regions in both hemispheres, including the tropical Pacific and Indian oceans, southeastern Asia, middle Asia (regions closed to the Caspian Sea), Australia, northeastern South America (i.e., Amazonia) and the Pacific coast of North and South America. The impacts of NAO are mainly found in the North Atlantic and European regions, while the notable influence of the IOD is limited in the western tropical Indian Ocean and part of the eastern tropical Pacific. There is high agreement between models in simulating the effects of climate modes on evaporation of these regions. Despite more extreme IOD events being expected in the future (Cai et al., 2013, 2014), the spatial influences of the IOD on evaporation are slightly less significant in the 2006-2100 period compared to the 1906-2000 period. These results imply that the effects on evaporation of the extreme states of the IOD do not persist long enough to be significant. Moreover, in the climate system, the effects of these extreme IOD events might be compensated by the extreme events of other climate modes (e.g., ENSO). The weak impacts of ENSO, NAO and the IOD on evaporation of sev-
MODELS MEAN OF ENSO - EVAPORATION: PERIOD 1906-2000 MINUS PERIOD 2006-2100

(a)
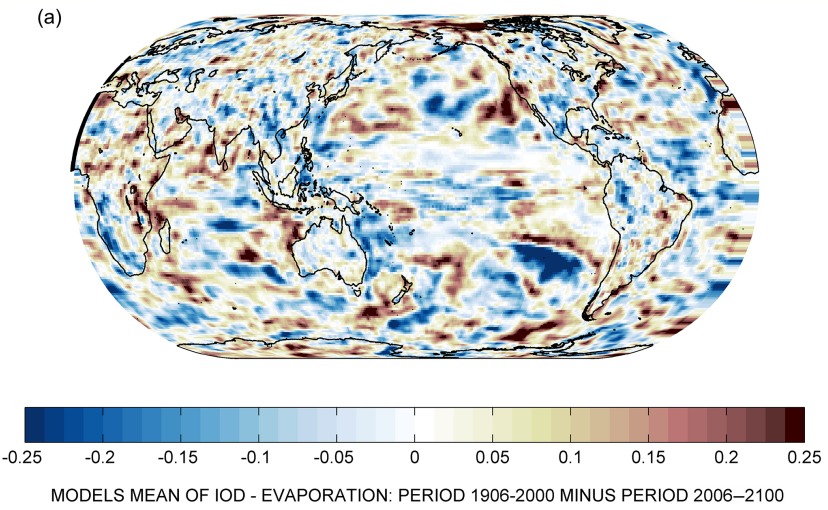

(b)
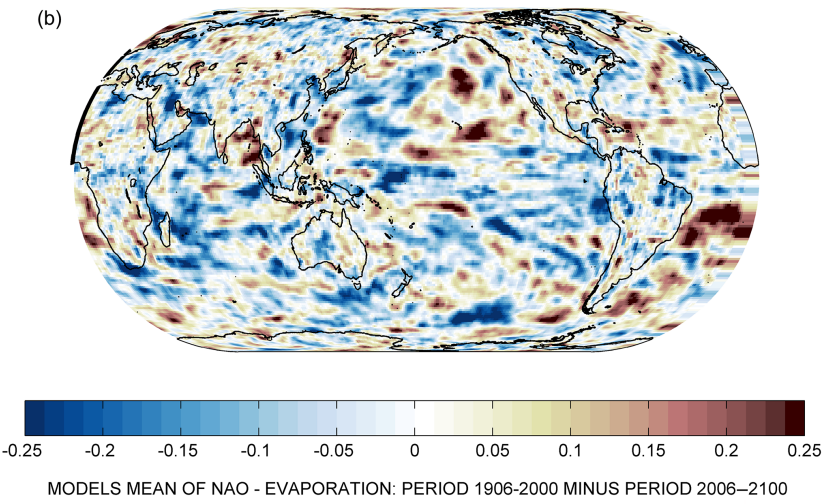

(c)
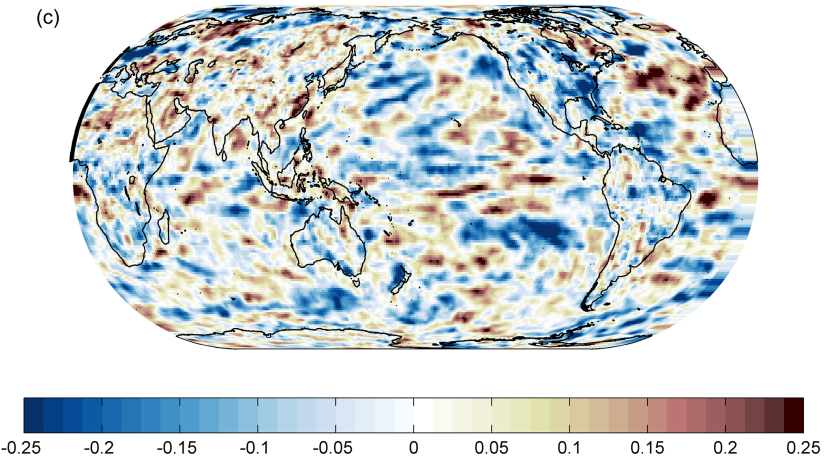

Figure 6. Difference of the probability for the absence of Granger causality of the individual climate mode on annual mean evaporation between the periods $1906-2000$ and 2006-2100 (i.e., period 1906-2000 minus period 2006-2100). The results are shown for ENSO (a), the IOD (b) and NAO (c). Blue shades indicate a lower probability of no Granger causality during the period 19062000 compared to the period 2006-2100. Brown shades indicate a lower probability of no Granger causality during the period 20062100 compared to the period 1906-2000. ENSO: El Niño-Southern Oscillation. NAO: North Atlantic Oscillation. IOD: Indian Ocean Dipole. 
MODELS MEAN OF PREDOMINANCE BETWEEN ENSO, NAO AND IOD - EVAPORATION: PERIOD 1906-2000

(a)
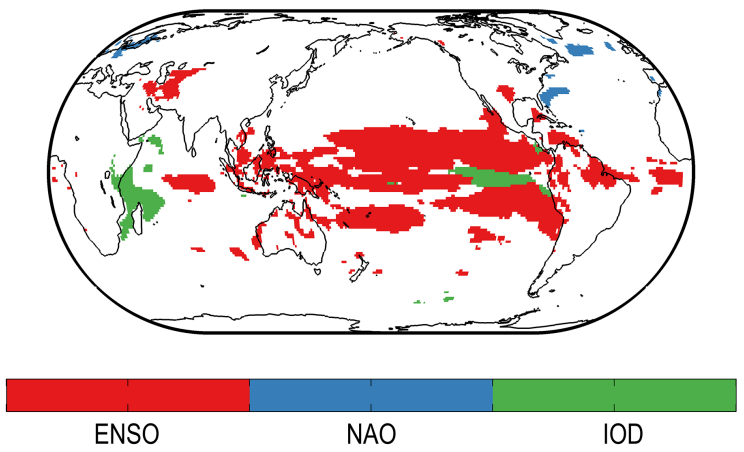

MODELS MEAN OF PREDOMINANCE BETWEEN ENSO, NAO AND IOD - EVAPORATION: PERIOD 2006-2100

(b)
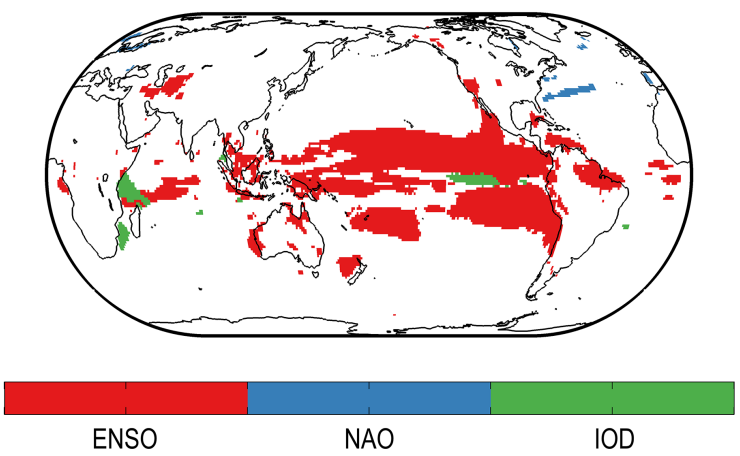

Figure 7. The predominance of a single climate mode on regional evaporation for periods 1906-2000 (a) and 2006-2100 (b). The predominance of a climate mode at a grid point is defined when the lowest $p$ value of all climate modes (see also Figs. 1, 2 and 3) at the given grid point is less than 0.25 (i.e., climate modes are unlikely to have no causal effects on evaporation). The predominance of ENSO, NAO and the IOD on evaporation are shown in red, blue and green shades, respectively. ENSO: El Niño-Southern Oscillation. NAO: North Atlantic Oscillation. IOD: Indian Ocean Dipole.

eral regions suggest the importance of external forcings (e.g., greenhouse gases, radiative forcing and solar forcing) and other climate modes on global evaporation variability. We emphasize the strong connection between considered climate modes (i.e., ENSO, the IOD and NAO) and oceanic evaporation at interannual timescales. Land evaporation is shown to have a weak connection with teleconnection indices in several regions, suggesting the weak effects of climate modes on important drivers of land evaporation, such as local wind speed (Stephens et al., 2018), surface temperature (Laîné et al., 2014; Miralles et al., 2013), moisture supply (Jung et al., 2010) and the amount of precipitation (Parr et al., 2016).

Our results may have suggestions for the predictability of regional evaporation (e.g., Australia, the tropical Pacific, the tropical Indian and North Atlantic oceans, the Pacific coast of North and South America, Amazonia, Europe, southeastern Asia and middle Asia) by using past time series of major climate modes for a short term of several years. The results of this study might provide information for drought and flood prediction as evaporation is an important metric for quantifying drought (McEvoy et al., 2016) and flood events.

Uncertainty regarding the impact of major climate modes on evaporation of several regions (e.g., ENSO impacts on evaporation of South Asia, South Africa, eastern North America, southern South America; the IOD impacts on western Africa and South Asia; and the NAO impacts on the North Atlantic and surrounding areas) suggests that additional works are necessary. Further investigation about the effects of other internal climate modes (e.g., the Southern Annular Mode, the Indian Ocean basin - IOB - mode and the North Tropical Atlantic - NTA - mode) on evaporation might improve our understanding of the response of the global hydrological cycle to internal climate variability. Little effort has been made to quantify the influences of external climate factors (i.e., volcanic eruptions, solar variations and changes in the concentration of greenhouse gases) on global evaporation; thus, these analyses might be a subject of forthcoming studies.

Data availability. CMIP data can be downloaded from the ESGF website at https://esgf-data.dkrz.de/search/cmip5-dkrz/ (ESGF, 2019) . The World Climate Research Programme's Working Group on Coupled Modeling is responsible for CMIP. The climate modeling groups (listed in Table S1 of this paper) are responsible for producing and making available their model output.

Supplement. The supplement related to this article is available online at: https://doi.org/10.5194/hess-24-1131-2020-supplement.

Author contributions. TL designed the study, performed the data analysis and wrote the paper. DHB supervised the project, contributed to the interpretation of results and the writing of the paper.

Competing interests. The authors declare that they have no conflict of interest.

Acknowledgements. We thank Ryan Teuling, Brecht Martens and Jasper Denissen for valuable comments and suggestions. We acknowledge the World Climate Research Programme's Working Group on Coupled Modeling, which is responsible for CMIP, and we thank the climate modeling groups (listed in Table S1 of this paper) for producing and making available their model output. For CMIP, the US Department of Energy's Program for Climate Model Diagnosis and Intercomparison provided coordinating support and led the development of software infrastructure in partnership with the Global Organization for Earth System Science Portals. Thanh Le is supported by a research grant from Sejong University. This work was supported by the Korea Environmental Industry and Technology Institute through the Advanced Water Management Research Program, funded by the South Korean Ministry of Environment (grant no. 83079). 
Financial support. This research has been supported by the Korea Environmental Industry and Technology Institute through Advanced Water Management Research Program, funded by the South Korean Ministry of Environment (grant no. 83079).

Review statement. This paper was edited by Ryan Teuling and reviewed by Jasper Denissen and one anonymous referee.

\section{References}

Abram, N. J., Gagan, M. K., McCulloch, M. T., Chappell, J., and Hantoro, W. S.: Coral reef death during the 1997 Indian Ocean Dipole linked to Indonesian wildfires, Science, 301, 952-955, https://doi.org/10.1126/science.1094047, 2003.

Arora, A., Rao, S. A., Chattopadhyay, R., Goswami, T., George, G., and Sabeerali, C. T.: Role of Indian Ocean SST variability on the recent global warming hiatus, Global Planet. Change, 143, 21-30, https://doi.org/10.1016/j.gloplacha.2016.05.009, 2016.

Ashok, K., Guan, Z., and Yamagata, T.: Influence of the Indian Ocean Dipole on the Australian winter rainfall, Geophys. Res. Lett., 30, 3-6, https://doi.org/10.1029/2003GL017926, 2003.

Behera, S. K., Luo, J. J., Masson, S., Rao, S. A., Sakuma, H., and Yamagata, T.: A CGCM study on the interaction between IOD and ENSO, J. Climate, 19, 1688-1705, https://doi.org/10.1175/JCLI3797.1, 2006.

Bjerknes, J.: Atmospheric Teleconnections From the Equatorial Pacific, Mon. Weather Rev., 97, 163-172, https://doi.org/10.1175/15200493(1969)097<0163:ATFTEP>2.3.CO;2, 1969.

Black, E., Slingo, J. M., and Sperber, K. R.: An observational study of the relationship between excessively strong short rains in coastal East Africa and Indian Ocean SST, Mon. Weather Rev., 74-94, https://doi.org/10.1175/15200493(2003)131<0074:AOSOTR>2.0.CO;2, 2003.

Cai, W., Cowan, T., and Sullivan, A.: Recent unprecedented skewness towards positive Indian Ocean Dipole occurrences and its impact on Australian rainfall, Geophys. Res. Lett., 36, 1-4, https://doi.org/10.1029/2009GL037604, 2009.

Cai, W., Sullivan, A., and Cowan, T.: Interactions of ENSO, the IOD, and the SAM in CMIP3 models, J. Climate, 24, 1688-1704, https://doi.org/10.1175/2010JCLI3744.1, 2011.

Cai, W., Zheng, X.-T., Weller, E., Collins, M., Cowan, T., Lengaigne, M., Yu, W., and Yamagata, T.: Projected response of the Indian Ocean Dipole to greenhouse warming, Nat. Geosci., 6, 999-1007, https://doi.org/10.1038/ngeo2009, 2013.

Cai, W., Santoso, A., Wang, G., Weller, E., Wu, L., Ashok, K., Masumoto, Y., and Yamagata, T.: Increased frequency of extreme Indian Ocean Dipole events due to greenhouse warming, Nature, 510, 254-258, https://doi.org/10.1038/nature13327, 2014.

Cai, W., Wang, G., Santoso, A., McPhaden, M. J., Wu, L., Jin, F.-F., Timmermann, A., Collins, M., Vecchi, G., Lengaigne, M., England, M. H., Dommenget, D., Takahashi, K., and Guilyardi, E.: Increased frequency of extreme La Niña events under greenhouse warming, Nat. Clim. Chang., 5, 132-137, https://doi.org/10.1038/nclimate2492, 2015.

Cai, W., Wu, L., Lengaigne, M., Li, T., McGregor, S., Kug, J.S., Yu, J.-Y., Stuecker, M. F., Santoso, A., Li, X., Ham, Y.-
G., Chikamoto, Y., Ng, B., McPhaden, M. J., Du, Y., Dommenget, D., Jia, F., Kajtar, J. B., Keenlyside, N., Lin, X., Luo, J.-J., Martín-Rey, M., Ruprich-Robert, Y., Wang, G., Xie, S.-P., Yang, Y., Kang, S. M., Choi, J.-Y., Gan, B., Kim, G.-I., Kim, C.-E., Kim, S., Kim, J.-H., and Chang, P.: Pantropical climate interactions, Science, 363, eaav4236, https://doi.org/10.1126/SCIENCE.AAV4236, 2019.

Cavusoglu, A. H., Chen, X., Gentine, P., and Sahin, O.: Potential for natural evaporation as a reliable renewable energy resource, Nat. Commun., 8, 617, https://doi.org/10.1038/s41467-017-00581-w, 2017.

Cheng, L., Zhang, L., Wang, Y. P., Canadell, J. G., Chiew, F. H. S., Beringer, J., Li, L., Miralles, D. G., Piao, S., and Zhang, Y.: Recent increases in terrestrial carbon uptake at little cost to the water cycle, Nat. Commun., 8, 110, https://doi.org/10.1038/s41467017-00114-5, 2017

Chu, J. E., Ha, K. J., Lee, J. Y., Wang, B., Kim, B. H., and Chung, C. E.: Future change of the Indian Ocean basin-wide and dipole modes in the CMIP5, Clim. Dynam., 43, 535-551, https://doi.org/10.1007/s00382-013-2002-7, 2014.

Dai, A. and Wigley, T. M. L.: Global patterns of ENSO-induced precipitation., Geophys. Res. Lett., 27, 1283-1286, 2000.

Diawara, A., Tachibana, Y., Oshima, K., Nishikawa, H., and Ando, Y.: Synchrony of trend shifts in Sahel boreal summer rainfall and global oceanic evaporation, 1950-2012, Hydrol. Earth Syst Sci., 20, 3789-3798, https://doi.org/10.5194/hess-20-3789-2016, 2016.

Dong, B. and Dai, A.: The uncertainties and causes of the recent changes in global evapotranspiration from 1982 to 2010 , Clim. Dynam., 49, 279-296, https://doi.org/10.1007/s00382016-3342-x, 2017.

Earth System Grid Federation (ESGF): CMIP5 (Coupled Model Intercomparison Project Phase 5), available at: https://esgf-data. dkrz.de/search/cmip5-dkrz/, last access: 15 November 2019.

Friedrich, K., Grossman, R. L., Huntington, J., Blanken, P. D., Lenters, J., Holman, K. D., Gochis, D., Livneh, B., Prairie, J., Skeie, E., Healey, N. C., Dahm, K., Pearson, C., Finnessey, T., Hook, S. J., and Kowalski, T.: Reservoir Evaporation in the Western United States: Current Science, Challenges, and Future Needs, B. Am. Meteorol. Soc., 99, 167-187, https://doi.org/10.1175/BAMS-D-15-00224.1, 2018.

Gong, H., Wang, L., Chen, W., Chen, X., and Nath, D.: Biases of the wintertime Arctic Oscillation in CMIP5 models, Environ. Res. Lett., 12, 014001, https://doi.org/10.1088/17489326/12/1/014001, 2017.

Gonsamo, A., Chen, J. M., and Lombardozzi, D.: Global vegetation productivity response to climatic oscillations during the satellite era, Glob. Change Biol., 22, 3414-3426, https://doi.org/10.1111/gcb.13258, 2016.

Hegerl, G. C., Black, E., Allan, R. P., Ingram, W. J., Polson, D., Trenberth, K. E., Chadwick, R. S., Arkin, P. A., Sarojini, B. B., Becker, A., Dai, A., Durack, P. J., Easterling, D., Fowler, H. J., Kendon, E. J., Huffman, G. J., Liu, C., Marsh, R., New, M., Osborn, T. J., Skliris, N., Stott, P. A., Vidale, P.-L., Wijffels, S. E., Wilcox, L. J., Willett, K. M., and Zhang, X.: Challenges in Quantifying Changes in the Global Water Cycle, B. Am. Meteorol. Soc., 96, 1097-1115, https://doi.org/10.1175/BAMS-D-13$00212.1,2015$. 
Hurrell, J. W., Kushnir, Y., Ottersen, G., and Visbeck, M.: An overview of the North Atlantic Oscillation, in Geophysical Monograph American Geophysical Union, American Geophysical Union, 1-35, 2003.

Izumo, T., Vialard, J., Lengaigne, M., de Boyer Montegut, C., Behera, S. K., Luo, J.-J., Cravatte, S., Masson, S., and Yamagata, T.: Influence of the state of the Indian Ocean Dipole on the following year's El Niño, Nat. Geosci., 3, 168-172, https://doi.org/10.1038/ngeo760, 2010.

Jung, M., Reichstein, M., Ciais, P., Seneviratne, S. I., Sheffield, J., Goulden, M. L., Bonan, G., Cescatti, A., Chen, J., De Jeu, R., Dolman, A. J., Eugster, W., Gerten, D., Gianelle, D., Gobron, N., Heinke, J., Kimball, J., Law, B. E., Montagnani, L., Mu, Q., Mueller, B., Oleson, K., Papale, D., Richardson, A. D., Roupsard, O., Running, S., Tomelleri, E., Viovy, N., Weber, U., Williams, C., Wood, E., Zaehle, S., and Zhang, K.: Recent decline in the global land evapotranspiration trend due to limited moisture supply, Nature, 467, 951-954, https://doi.org/10.1038/nature09396, 2010.

Kitoh, A.: The Asian Monsoon and its Future Change in Climate Models: A Review, J. Meteorol. Soc. Jpn. Ser. II, 95, 7-33, https://doi.org/10.2151/jmsj.2017-002, 2016.

Kripalani, R. H., Oh, J. H., and Chaudhari, H. S.: Delayed influence of the Indian Ocean Dipole mode on the East Asia-West Pacific monsoon: possible mechanism, Int. J. Climatol., 30, 197-209, https://doi.org/10.1002/joc.1890, 2009.

Laîné, A., Nakamura, H., Nishii, K., and Miyasaka, T.: A diagnostic study of future evaporation changes projected in CMIP5 climate models, Clim. Dynam., 42, 2745-2761, https://doi.org/10.1007/s00382-014-2087-7, 2014.

Le, T.: Solar forcing of Earth's surface temperature in PMIP3 simulations of the last millennium, Atmos. Sci. Lett., 16, 285-290, https://doi.org/10.1002/asl2.555, 2015.

Le, T. and Bae, D.-H.: Causal links on interannual timescale between ENSO and the IOD in CMIP5 future simulations, Geophys. Res. Lett., 46, 2820-2828, https://doi.org/10.1029/2018GL081633, 2019.

Le, T., Sjolte, J., and Muscheler, R.: The influence of external forcing on subdecadal variability of regional surface temperature in CMIP5 simulations of the last millennium, J. Geophys. Res.-Atmos., 121, 1671-1682, https://doi.org/10.1002/2015JD024423, 2016.

Lee, J., Sperber, K. R., Gleckler, P. J., Bonfils, C. J. W., and Taylor, K. E.: Quantifying the agreement between observed and simulated extratropical modes of interannual variability, Springer Berlin Heidelberg, Germany, 2018.

Lee, M. H., Im, E. S., and Bae, D. H.: A comparative assessment of climate change impacts on drought over Korea based on multiple climate projections and multiple drought indices, Clim. Dynam., 53, 389-404, https://doi.org/10.1007/s00382-018-4588-2, 2019.

Leung, M. Y. T. and Zhou, W.: Direct and indirect ENSO modulation of winter temperature over the Asian-Pacific-American region, Sci. Rep., 6, 1-7, https://doi.org/10.1038/srep36356, 2016.

Liu, X., Luo, Y., Zhang, D., Zhang, M., and Liu, C.: Recent changes in pan-evaporation dynamics in China, Geophys. Res. Lett., 38, 10-13, https://doi.org/10.1029/2011GL047929, 2011.

Martens, B., Waegeman, W., Dorigo, W. A., Verhoest, N. E. C., and Miralles, D. G.: Terrestrial evaporation response to modes of climate variability, npj Clim. Atmos. Sci., 1, 43, https://doi.org/10.1038/s41612-018-0053-5, 2018.

McEvoy, D. J., Huntington, J. L., Mejia, J. F., and Hobbins, M. T.: Improved seasonal drought forecasts using reference evapotranspiration anomalies, Geophys. Res. Lett., 43, 377-385, https://doi.org/10.1002/2015GL067009, 2016.

McPhaden, M. J., Zebiak, S. E., and Glantz, M. H.: ENSO as an integrating concept in earth science, Science, 314, 1740-1745, https://doi.org/10.1126/science.1132588, 2006.

Miralles, D. G., Van Den Berg, M. J., Teuling, A. J., and De Jeu, R. A. M.: Soil moisture-temperature coupling: A multiscale observational analysis, Geophys. Res. Lett., 39, 2-7, https://doi.org/10.1029/2012GL053703, 2012.

Miralles, D. G., van den Berg, M. J., Gash, J. H., Parinussa, R. M., de Jeu, R. A. M., Beck, H. E., Holmes, T. R. H., Jiménez, C., Verhoest, N. E. C., Dorigo, W. A., Teuling, A. J., and Johannes Dolman, A.: El Niño-La Niña cycle and recent trends in continental evaporation, Nat. Clim. Chang., 4, 1-5, https://doi.org/10.1038/nclimate2068, 2013.

Miralles, D. G., Jiménez, C., Jung, M., Michel, D., Ershadi, A., McCabe, M. F., Hirschi, M., Martens, B., Dolman, A. J., Fisher, J. B., Mu, Q., Seneviratne, S. I., Wood, E. F., and Fernández-Prieto, D.: The WACMOS-ET project - Part 2: Evaluation of global terrestrial evaporation data sets, Hydrol. Earth Syst. Sci., 20, 823 842, https://doi.org/10.5194/hess-20-823-2016, 2016.

Mosedale, T. J., Stephenson, D. B., Collins, M., and Mills, T. C.: Granger causality of coupled climate processes: Ocean feedback on the North Atlantic Oscillation, J. Climate, 19, 1182-1194, https://doi.org/10.1175/JCLI3653.1, 2006.

Mueller, B. and Seneviratne, S. I.: Systematic land climate and evapotranspiration biases in CMIP5 simulations, Geophys. Res. Lett., 41, 128-134, https://doi.org/10.1002/2013GL058055, 2014.

Naumann, G., Alfieri, L., Wyser, K., Mentaschi, L., Betts, R. A., Carrao, H., Spinoni, J., Vogt, J., and Feyen, L.: Global Changes in Drought Conditions Under Different Levels of Warming, Geophys. Res. Lett., 45, 3285-3296, https://doi.org/10.1002/2017GL076521, 2018.

Neelin, J. D., Battisti, D. S., Hirst, A. C., Jin, F.-F., Wakata, Y., Yamagata, T., and Zebiak, S. E.: ENSO theory, J. Geophys. Res., 103, 14261, https://doi.org/10.1029/97JC03424, 1998.

Nicolai-Shaw, N., Gudmundsson, L., Hirschi, M., and Seneviratne, S. I.: Long-term predictability of soil moisture dynamics at the global scale: Persistence versus large-scale drivers, Geophys. Res. Lett., 43, 8554-8562, https://doi.org/10.1002/2016GL069847, 2016.

Parr, D., Wang, G., and Fu, C.: Understanding evapotranspiration trends and their driving mechanisms over the NLDAS domain based on numerical experiments using CLM4.5, J. Geophys. Res.-Atmos., 121, 7729-7745, https://doi.org/10.1002/2015JD024398, 2016.

Saji, N. H., Vinayachandran, P. N., and Yamagata, T.: A dipole in the tropical Indian Ocean, Nature, 401, 360-363, 1999.

Schwarz, G.: Estimating the dimension of a model, Ann. Statist., 6, 461-464, https://doi.org/10.1214/aos/1176344136, 1978.

Shinoda, T. and Han, W.: Influence of the Indian Ocean dipole on atmospheric subseasonal variability, J. Climate, 18, 3891-3909, https://doi.org/10.1175/JCLI3510.1, 2005. 
Son, K. H. and Bae, D. H.: Drought analysis according to shifting of climate zones to arid climate zone over Asia monsoon region, J. Hydrol., 529, 1021-1029, https://doi.org/10.1016/j.jhydrol.2015.09.010, 2015.

Stephens, C. M., McVicar, T. R., Johnson, F. M., and Marshall, L. A.: Revisiting Pan Evaporation Trends in Australia a Decade on, Geophys. Res. Lett., 45, 11164-11172, https://doi.org/10.1029/2018GL079332, 2018.

Stern, D. I. and Kaufmann, R. K.: Anthropogenic and natural causes of climate change, Climatic Change, 122, 257-269, https://doi.org/10.1007/s10584-013-1007-x, 2013.

Stocker, T. F., D. Qin, G.-K., Plattner, L. V., Alexander, S. K., Allen, N. L., Bindoff, F.-M., Bréon, J. A., Church, U., Cubasch, S., Emori, P., Forster, P., Friedlingstein, N., Gillett, J. M., Gregory, D. L., Hartmann, E., Jansen, B., Kirtman, R., Knutti, K., Krishna Kumar, P., Lemke, J., Marotzke, V., Masson-Delmotte, G. A., Meehl, I. I., Mokhov, S., Piao, V., Ramaswamy, D., Randall, M., Rhein, M., Rojas, C., Sabine, D., Shindell, L. D., Talley, D. G., Xie, V., and Xie, S.-P.: Technical Summary, in: Climate Change 2013 - The Physical Science Basis, edited by: Intergovernmental Panel on Climate Change, 31-116, Cambridge University Press, Cambridge, https://doi.org/10.1017/CBO9781107415324.005, 2013.

Sun, C., Li, J., and Ding, R.: Strengthening relationship between ENSO and western Russian summer surface temperature, Geophys. Res. Lett., 43, 843-851, https://doi.org/10.1002/2015GL067503, 2016.

Taschetto, A. S., Gupta, A. Sen, Jourdain, N. C., Santoso, A., Ummenhofer, C. C., and England, M. H.: Cold tongue and warm pool ENSO Events in CMIP5: Mean state and future projections, J. Climate, 27, 2861-2885, https://doi.org/10.1175/JCLI-D-13$00437.1,2014$.

Taylor, K. E., Stouffer, R. J., and Meehl, G. A.: An Overview of CMIP5 and the Experiment Design, B. Am. Meteorol. Soc., 93, 485-498, https://doi.org/10.1175/BAMS-D-11-00094.1, 2012.

Teuling, A. J., Taylor, C. M., Meirink, J. F., Melsen, L. A., Miralles, D. G., Van Heerwaarden, C. C., Vautard, R., Stegehuis, A. I., Nabuurs, G. J., and De Arellano, J. V. G.: Observational evidence for cloud cover enhancement over western European forests, Nat. Commun., 8, 1-7, https://doi.org/10.1038/ncomms14065, 2017.

Thirumalai, K., DInezio, P. N., Okumura, Y., and Deser, C.: Extreme temperatures in Southeast Asia caused by El Ninõ and worsened by global warming, Nat. Commun., 8, 1-8, https://doi.org/10.1038/ncomms15531, 2017.

Ummenhofer, C. C., England, M. H., Mclntosh, P. C., Meyers, G. A., Pook, M. J., Risbey, J. S., Sen Gupta, A., and Taschetto, A. S.: What causes southeast Australia's worst droughts?, Geophys. Res. Lett., 36, 1-5, https://doi.org/10.1029/2008GL036801, 2009.

van Osnabrugge, B., Uijlenhoet, R., and Weerts, A.: Contribution of potential evaporation forecasts to 10-day streamflow forecast skill for the Rhine River, Hydrol. Earth Syst. Sci., 23, 14531467, https://doi.org/10.5194/hess-23-1453-2019, 2019. van Vuuren, D. P., Edmonds, J., Kainuma, M., Riahi, K., Thomson, A., Hibbard, K., Hurtt, G. C., Kram, T., Krey, V., Lamarque, J. F., Masui, T., Meinshausen, M., Nakicenovic, N., Smith, S. J., and Rose, S. K.: The representative concentration pathways: An overview, Climatic Change, 109, 5-31, https://doi.org/10.1007/s10584-011-0148-z, 2011.

Wang, K. and Dickinson, R. E.: A review of global terrestrial evapotranspiration: Observation, modeling, climatology, and climatic variability, Rev. Geophys., 50, 1-54, https://doi.org/10.1029/2011RG000373, 2012.

Wang, X., Li, J., Sun, C., and Liu, T.: NAO and its relationship with the Northern Hemisphere mean surface temperature in CMIP5 simulations, J. Geophys. Res., 122, 4202-4227, https://doi.org/10.1002/2016JD025979, 2017.

Webster, P. J., Moore, A. M., Loschnigg, J. P., and Leben, R. R.: Coupled ocean-atmosphere dynamics in the Indian Ocean during 1997-98, Nature, 401, 356-360, https://doi.org/10.1038/43848, 1999.

Wei, J., Jin, Q., Yang, Z. L., and Dirmeyer, P. A.: Role of ocean evaporation in California droughts and floods, Geophys. Res. Lett., 43, 6554-6562, https://doi.org/10.1002/2016GL069386, 2016.

Weigel, A. P., Knutti, R., Liniger, M. A., and Appenzeller, C.: Risks of Model Weighting in Multimodel Climate Projections, J. Climate, 23, 4175-4191, https://doi.org/10.1175/2010JCLI3594.1, 2010.

Weller, E. and Cai, W.: Realism of the indian ocean dipole in CMIP5 models: The implications for climate projections, J. Climate, 26, 6649-6659, https://doi.org/10.1175/JCLI-D-12-00807.1, 2013.

Xing, W., Wang, W., Shao, Q., Yu, Z., Yang, T., and Fu, J.: Periodic fluctuation of reference evapotranspiration during the past five decades: Does Evaporation Paradox really exist in China?, Sci. Rep., 6, 1-12, https://doi.org/10.1038/srep39503, 2016.

Yeh, S. W., Cai, W., Min, S. K., McPhaden, M. J., Dommenget, D., Dewitte, B., Collins, M., Ashok, K., An, S.-I., Yim, B. Y., and Kug, J. S.: ENSO Atmospheric Teleconnections and Their Response to Greenhouse Gas Forcing, Rev. Geophys., 56, 185206, https://doi.org/10.1002/2017RG000568, 2018.

Zanardo, S., Nicotina, L., Hilberts, A. G. J., and Jewson, S. P.: Modulation of Economic Losses From European Floods by the North Atlantic Oscillation, Geophys. Res. Lett., 46, 2563-2572, https://doi.org/10.1029/2019GL081956, 2019.

Zhang, Q., Yang, Z., Hao, X., and Yue, P.: Conversion features of evapotranspiration responding to climate warming in transitional climate regions in northern China, Clim. Dynam., 52, 38913903, https://doi.org/10.1007/s00382-018-4364-3, 2018.

Zveryaev, I. I. and Hannachi, A. A.: Interannual variability of Mediterranean evaporation and its relation to regional climate, Clim. Dynam., 38, 495-512, https://doi.org/10.1007/s00382011-1218-7, 2011. 